\title{
Equity in the finance of health care: Some international comparisons*
}

\author{
Adam Wagstaff \\ University of Sussex, Brighton, $U K$ \\ Eddy van Doorslaer** \\ Erasmus University, Rotterdam, Netherlands
}

Final version received July 1992

This paper presents the results of a ten-country comparative study of health care financing systems and their progressivity characteristics. It distinguishes between the tax-financed systems of Denmark, Portugal and the U.K., the social insurance systems of France, the Netherlands and Spain, and the predominantly private systems of Switzerland and the U.S. It concludes that tax-financed systems tend to be proportional or mildly progressive, that social insurance systems are regressive and that private systems are even more regressive. Out-of-pocket payments are in most countries an especially regressive means of raising health care revenues.

\section{Introduction}

Health care reform looks set to stay high on the policy-making agenda in the 1990s. Some of the reforms that were planned during the 1980 s have already begun to be implemented. These include the so-called internal market programme in Britain, the move from fee-for-service to capitation payments for low-income patients of GPs in Ireland and the switch from social insurance to tax-financing in Spain. Other reforms are likely to follow elsewhere. Some variant on the 1988 Dekker Plan aimed at promoting competition amongst insurers and providers is likely to be implemented in the Netherlands in the early 1990s. The Swiss are shortly to vote in a referendum proposing a large increase in the role of taxation in the financing

Correspondence to: Adam Wagstaff, School of Social Sciences, Arts Building, University of Sussex, Brighton BN1 9QN, UK.

*We are grateful to the European Community's COMAC-Health Services Research Committee, which funded the coordination of the project whose results are reported in this paper, to Tony Culyer, Karen Davis, Jacques van der Gaag, Bob Haveman, Jeremy Hurst, Julian Le Grand, Jean-Pierre Poullier and Alan Williams for helpful comments on the research underlying this paper, and to Brigitte Kerbusch, Caroline Verboom and Jan van Emmerik for their assistance in the organization of the project.

${ }^{* *}$ And others. A full list of these authors and their affiliations appears in the Appendix. 
of health care. And reforms to the American health care system look increasingly likely, as health care costs and the number of uninsured continue to rise remorselessly.

Despite the widespread interest in health care reform, the debate so far has been somewhat parochial in character. Although Peet's (1991) claim that 'most countries are dealing with health care reform as if each was on Mars' is somewhat overstated, it is undoubtedly true that more can be learnt from cross-country comparisons than has been learnt up until now about the advantages and disadvantages associated with alternative methods of financing and delivering health care, and about the likely effects of health care reforms. Moreover, the few cross-country comparisons that have been undertaken to date have focussed mostly on expenditure comparisons, although some have tried to go further and address broader efficiency issues. ${ }^{1}$ The result is that remarkably little is known about the equity characteristics of alternative health care financing and delivery systems, and about the likely equity implications of reforms to these systems. This is despite the apparent importance attached to equity as a policy objective in most OECD countries. Indeed, some [McLachlan and Maynard (1982); Mooney (1986)] go so far as to claim that the public attaches greater importance to equity than to efficiency in health care.

This paper and an accompanying paper report the results of a comparative project which seeks to go some way towards filling this gap in the literature. ${ }^{2}$ Its aim was to generate cvidence on the comparative performance - in terms of equity - of different health care financing and delivery systems. The 10 countries which participated in the study - Denmark, France, Ireland, Italy, the Netherlands, Portugal, Spain, Switzerland, the U.K. and the U.S. - encompass the full spectrum of health care financing and delivery systems, ranging from the predominantly private U.S. system, through the mixed public-private social insurance systems of countries like France and the Netherlands, to the almost $100 \%$ public systems operating in Denmark and the U.K.

Besides its focus on equity, three other features of the project distinguish it from previous cross-country comparisons. One is that, in contrast to previous empirical studies of a comparative nature, which have almost all been based on aggregate data, the present study employs micro-level data. This is in line with the recommendation of Schieber and Poullier (1991), who, in their latest OECD comparative study, urged that greater use be made of micro-level data in cross-country comparisons in the health care field. A second feature of the present study is that those participating have

\footnotetext{
${ }^{1}$ For a recent study of health care expenditures see Gerdtham et al. (1992). For an attempt to move beyond expenditure comparisons to broader efficiency issues, see Culyer et al. (1981).

${ }^{2}$ The project was coordinated jointly by Frans Rutten, Eddy van Doorslaer and Adam Wagstaff.
} 
together developed and then applied a common methodology. There is, as a result, a high degree of comparability in the empirical results. Differences in results ought therefore to reflect genuine differences between countries rather than differences in methods. A third feature of the project is that the analysis for each of the 10 countries has been undertaken, for the most part, by research teams from the country in question. This contrasts with previous comparative studies in the health field where one or two researchers have invariably performed the analysis for all the countries in the study.

That equity is a goal that is pursued by policy-makers in all types of health care system is readily apparent. But what is equity? How should it be defined? And how is it to be measured? Answers to these questions are far from self-evident but are clearly required if meaningful cross-country comparisons are to be performed. It is sometimes suggested that academics and policy-makers agree much less over what they mean by equity than they do over what they mean by efficiency. McLachlan and Maynard (1982), for example, have suggested that :...equity, like beauty, is in the mind of the beholder...' (p. 520). As Le Grand (1987) notes, this view is not entirely justified. Examination of the relevant philosophy literature, as well as policy documents and empirical work in this field reveals, in fact, a reasonable degree of consensus.

Of the various theories of distributive justice that might be brought to bear on the issue of equity in healthy care, it is generally agreed that some have a greater applicability and acceptability than others. Gillon (1986), for example, argues that of the various distributive principles proposed by philosophers in this context, it is the egalitarian notion that health care ought to be distributed according to need which commands the greatest support among health professions and the public at large. This principle is often coupled, of course, with the principle of 'from each according to his ability to pay'.

A comparison of policy statements on equity in several OECD countries suggests that policy-makers are in broad agreement over what they mcan by equity, even if the precise details vary. There appears to be broad agreement, for example, among policy-makers in at least eight of the nine European countries in the present study that payments towards health care should be related to ability to pay rather than to use of medical facilities. ${ }^{3}$ Policymakers in all nine European countries also appear to be committed to the notion that all citizens should have access to health care. ${ }^{4}$ In many countries this is taken further, it being made clear that access to and receipt of health care should depend on need, rather than on ability to pay.

Finally, in empirical work, researchers from countries with such different

\footnotetext{
${ }^{3}$ Hurst (1992) concludes the same in his comparison of the health care sytems of Belgium, France, Germany, the Netherlands, Ireland, Spain and U.K.

${ }^{4}$ Again, the same conclusion has been reached by Hurst (1992) in his comparative study.
} 
health care systems as Britain and the United States have adopted much the same notions of equity in their analysis. Most studies of equity in the delivery of health care - in both Europe and the U.S. - start from the premise that health care ought to be distributed according to need, rather than willingness and ability to pay, and all empirical studies to date of equity in the finance of health care take as their starting point the premise that health care ought to be financed according to ability to pay. ${ }^{5}$

Contrary to what is sometimes claimed, then, there seems to be a broad measure of support for the notion that health care ought to be financed according to ability to pay and distributed according to need. It is this ethical premise that provides the point of departure of the present study. The remainder of this paper examines the issue of equity in the finance of health care focussing on progressivity, i.e. the extent to which families on higher incomes pay larger shares of their incomes towards health care. A companion paper [Van Doorslaer, Wagstaff et al. (1992)] examines the issue of equity in the delivery of health care, focussing on the horizontal equity aspect of health care provision, i.e. the extent to which persons in equal need are treated the same irrespective of their income.

The remainder of the paper is organized as follows. Section 2 outlines the principal differences across the 10 countries in their health care financing systems. Section 3 considers the problems associated with defining and measuring equity in the finance of health care, and seeks to justify the present project's focus on the issue of progressivity. Section 4 outlines the incidence assumptions employed, the data sources and the variable definitions. The next section - section 5 - presents the empirical results. The final section contains a summary and draws various conclusions.

\section{Cross-country differences in health care financing systems}

Countries typically finance the bulk of their health care expenditures from two or more of four sources: (i) general taxation, (ii) social insurance contributions, (iii) private insurance premiums, and (iv) out-of-pocket payments. There is, however, substantial variation across countries in both the way revenue is raised within each source and the relative importance of each source. As will be seen, both are important determinants of the overall progressivity of any health care financing system.

\subsection{Roles of financing sources}

Table 1 shows how revenue is raised from each source in each of the 10 countries in the present study. The year indicated is the year to which the

\footnotetext{
${ }^{5}$ See Hurst (1985), who compares the American, British and Canadian financing systems, and Gottschalk, Haveman and Wolfe (1989), who compare the American, British and Dutch systems.
} 
data used in the empirical analysis for the country in question refer. Only in two cases - Spain and Portugal - has there been a major change in the health care financing system since the year indicated in table 1 .

A variety of taxes are used to finance health care. Rarely are they earmarked. Usually, they are simply general tax revenues and include therefore both direct taxes (such as income tax) and indirect taxes (such as VAT). By contrast, social insurance revenues frequently are earmarked. This is true of countries like the Netherlands were social insurance takes the form of contributions to a sickness fund, but also of countries like Italy and the U.S. where social insurance takes the form of a payroll tax collected by the State. Whatever the precise system, contributions are compulsory for almost all the population (opting out, if allowed, tends to be restricted to persons with high earnings) and linked to earnings (contributions are frequently split between employee and employer, and are often proportional to earnings up to a ceiling). The role of private insurance also varies across countries. In some countries (e.g. the Netherlands and the U.S.) private insurance provides cover for persons without comprehensive public cover. In others (e.g. Italy, Portugal, Spain and the U.K.) private insurance provides supplementary (i.e. double) cover to persons who already have comprehensive public cover. In other countries still (e.g. Denmark and France) private insurance provides cover against public sector co-payments levied on prescription medicines, dental care, etc. In one country - Ireland - private insurance serves all three functions. Finally, the role of out-of-pocket payments varies somewhat across countries. In some (e.g. Denmark, France, Ireland, the Netherlands, the U.K. and the U.S.) they are predominantly co-payments, with a third party picking up (usually) the major share of the bill. In others (e.g. Italy, Portugal and Spain) there is extensive use of the private sector on a fee-paying basis.

\subsection{The financing mix}

The importance attached to each source of finance varies substantially across countries, as is apparent from fig. 1. Here 'general taxes' exclude any payroll taxes used to finance health care; these are included under 'social insurance'.

One important distinction is between financing systems that are predominantly public and those that are predominantly private. The U.S. and Switzerland stand out in fig. 1 as the only countries relying on out-of-pocket payments and private insurance premiums for the majority of their revenues. ${ }^{6}$ In the European countries other than Switzerland the picture is

\footnotetext{
${ }^{6}$ Switzerland is usually shown as being predominantly public [Maxwell (1981); OECD (1989)]. This is because the premiums paid to sickness funds for basic health insurance cover are recorded under social insurance in the Swiss national accounts. This practice is misleading, since these premiums are neither compulsory nor earnings-related.
} 

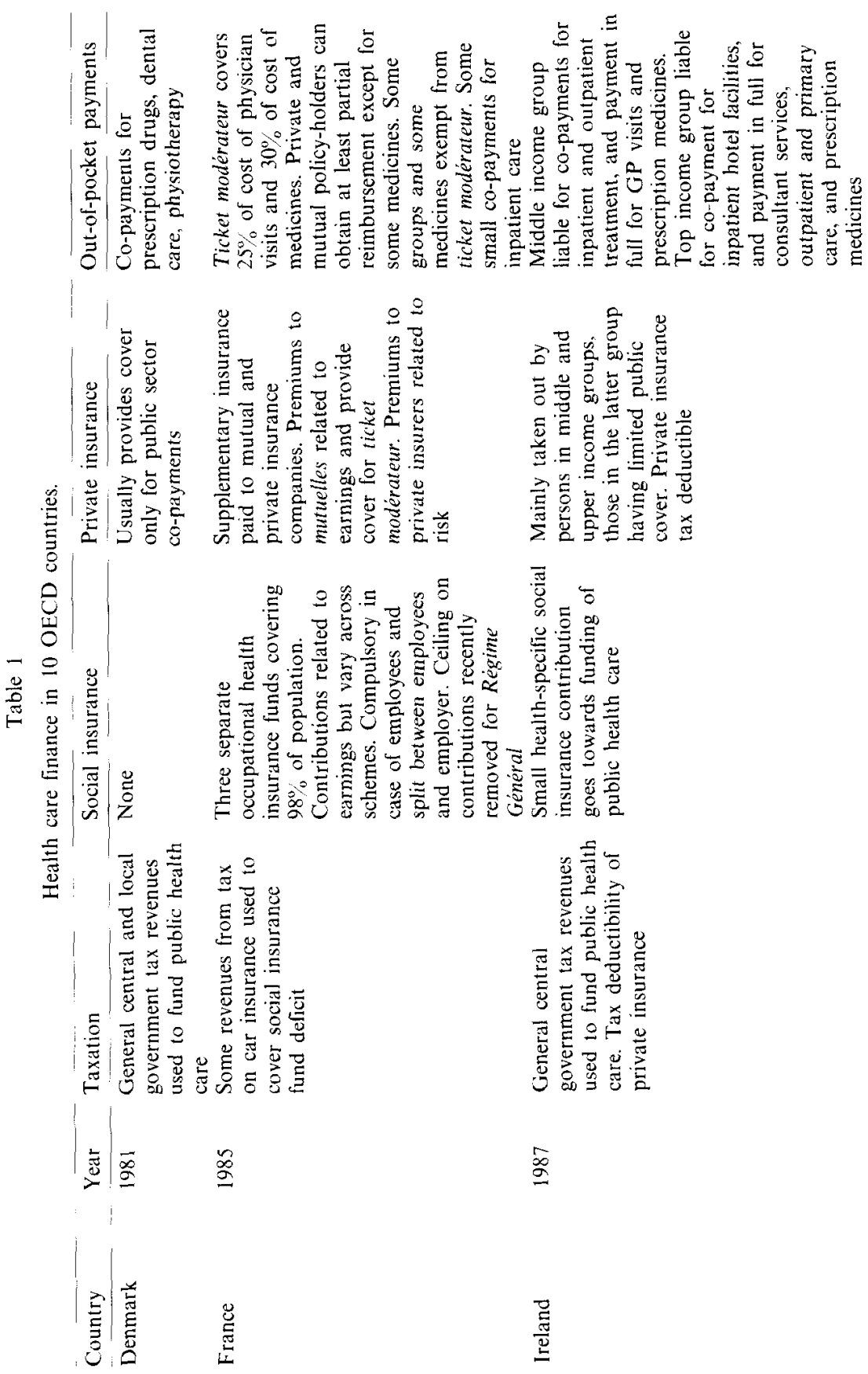

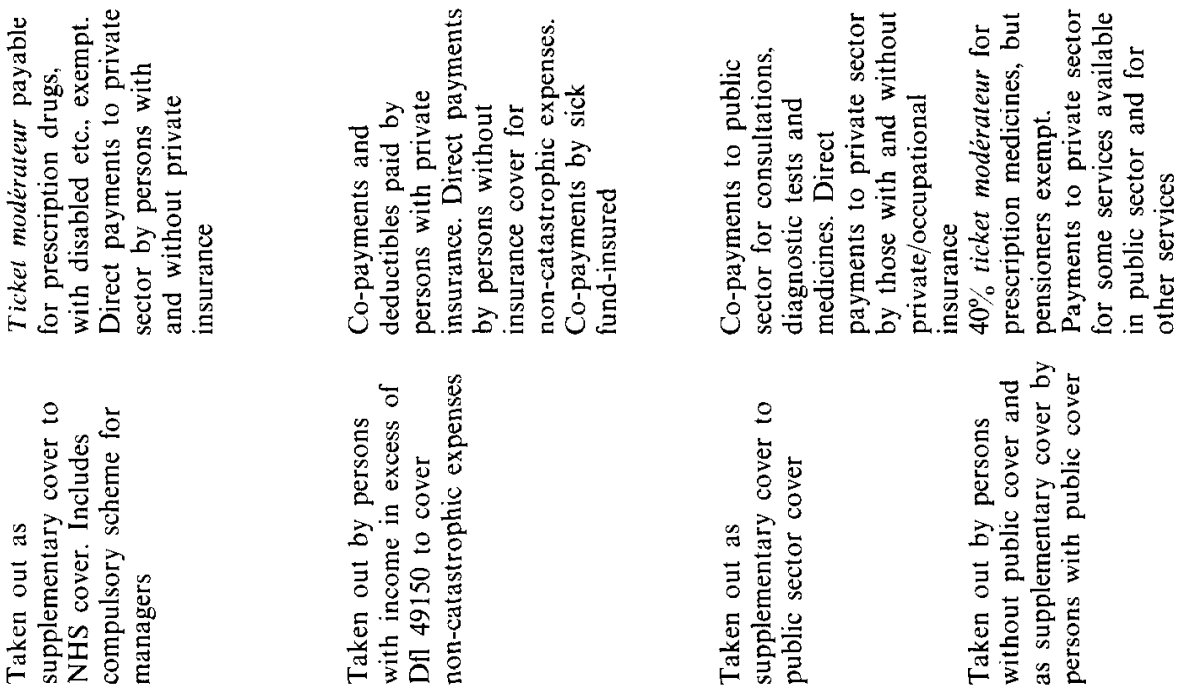

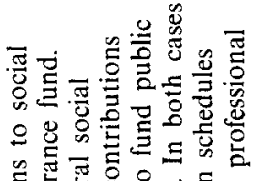

的 $>0$

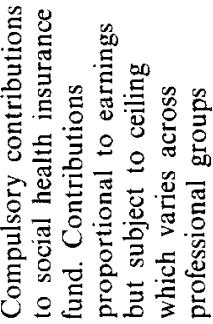

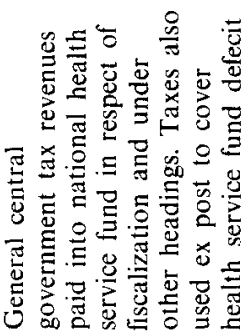

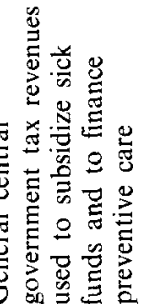

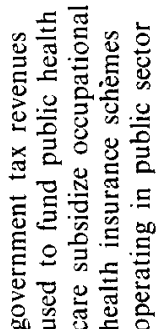

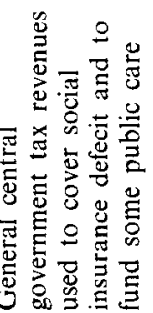

$\stackrel{\infty}{2}$

$\stackrel{2}{2}$

$\stackrel{\circ}{\circ}$

$\stackrel{\circ}{\circ}$

哑

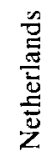

总

कํㅡㅁ 


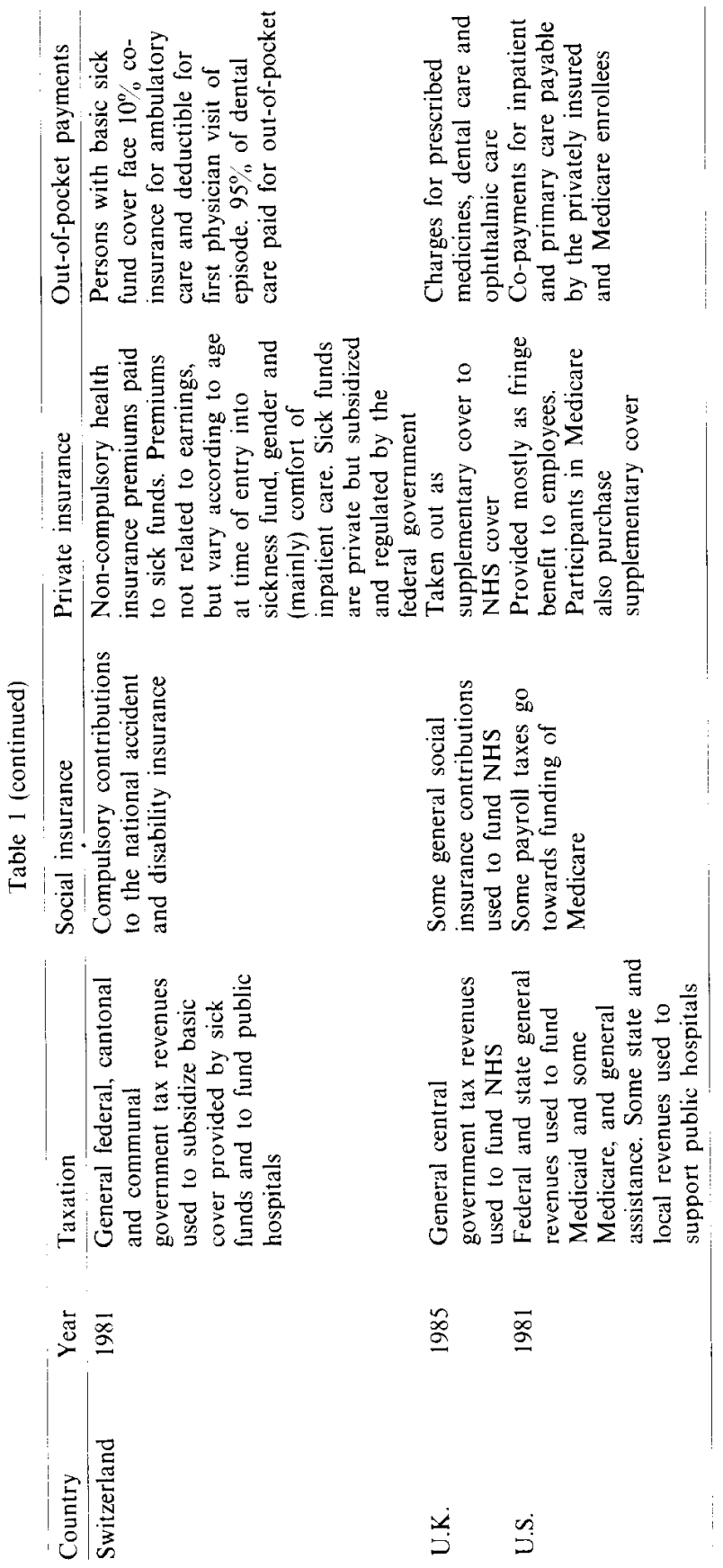




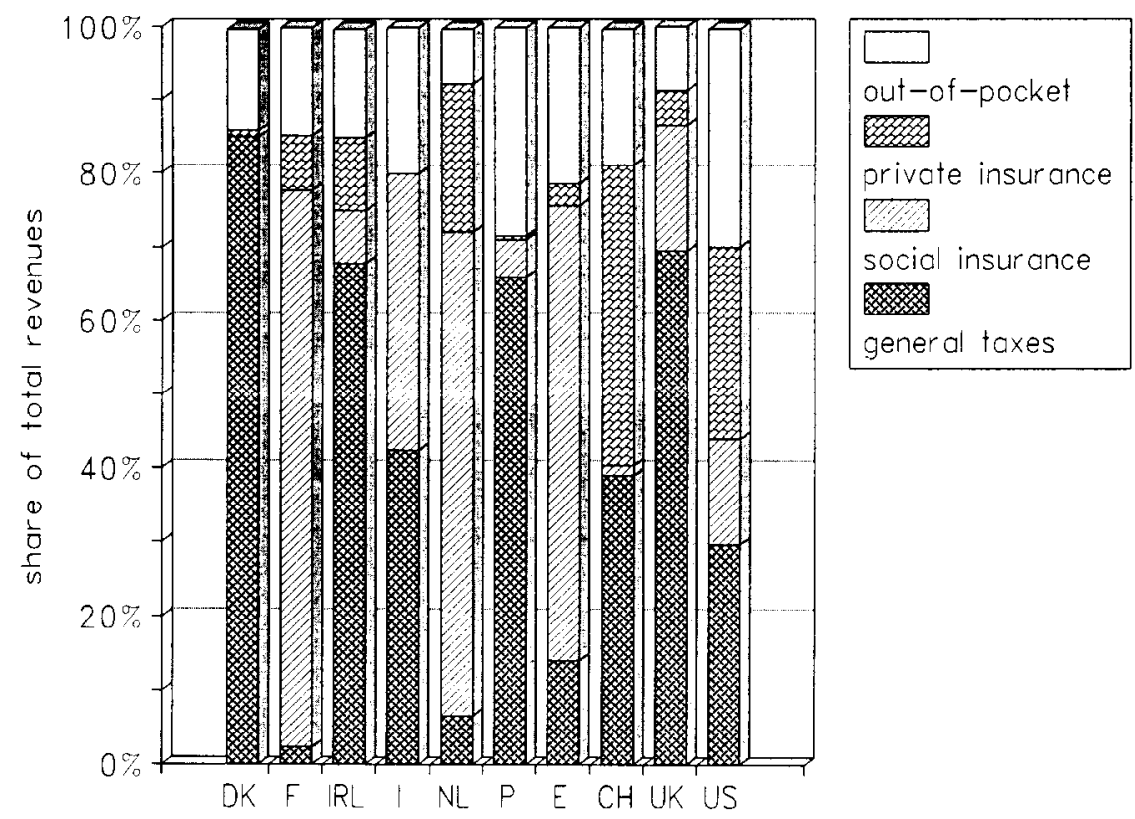

Fig. 1. Health care financing sources. Years indicated in table 3.

markedly different: private expenditures typically account for around one quarter of health care expenditures. There is, however, some variation: in the U.K. only $13.5 \%$ of expenditures are private of which $64 \%$ are out-of-pocket, whilst in Portugal in 1981 almost $30 \%$ was financed privately and virtually all was out-of-pocket. Moreover, this figure had grown to almost $40 \%$ in 1987, making Portugal the country with the highest share of health care paid for out-of-pocket.

Fig. 1 also reveals that in most countries (Switzerland and the Netherlands are exceptions) out-of-pocket payments account for the majority of private expenditures. Again, however, there is substantial variation: in Denmark and the three southern European countries almost all private expenditures are out-of-pocket, whilst in the U.S. private expenditures are almost equally divided between private insurance premiums and out-of-pocket payments.

Another important distinction is between social insurance-based public systems and tax-based public systems. In the year indicated in table 1, France, the Netherlands and Spain all financed the bulk of their public expenditures out of earmarked social insurance contributions. At the other extreme are Denmark, Ireland, Portugal, Switzerland and the U.K., where the majority of public expenditures are financed out of general taxation. 


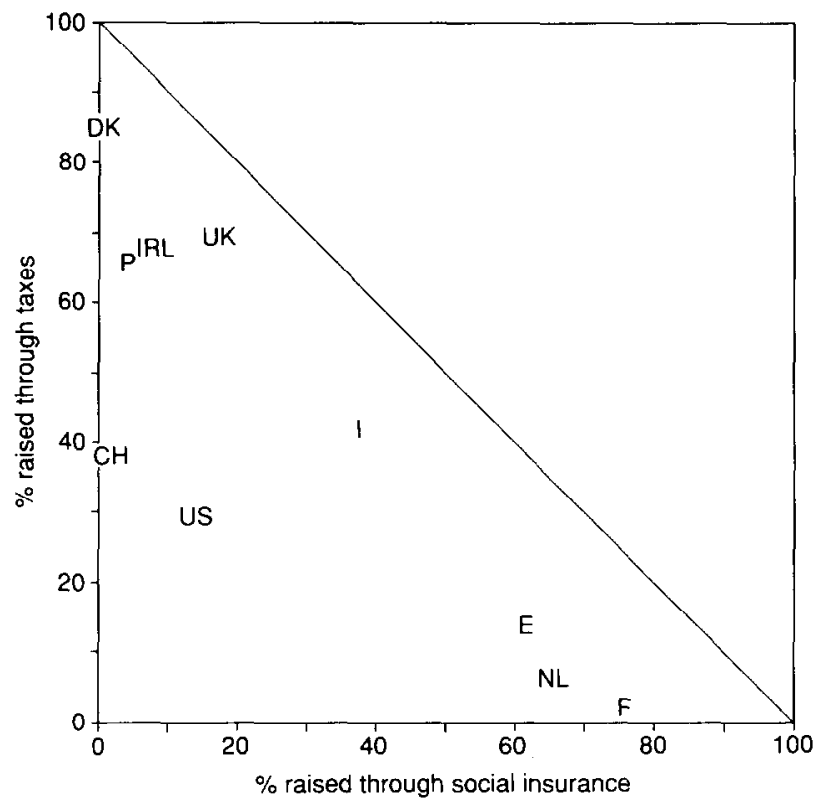

Fig. 2. Health care financing triangle.

Public health care expenditures in Italy and the U.S. are financed more or less equally from social insurance and general tax revenues.

The overall differences between countries in health care financing can be shown more clearly in the 'health care financing triangle' in fig. 2. The closer a country is to the bottom left-hand corner, the closer it is to being $100 \%$ private. Amongst the 10 countries in the study, Switerland and the U.S. are the most private. By contrast the closer a country is to the hypotenuse, the closer it is to being $100 \%$ public. Of the countries in the present study, Denmark and the U.K. have the most public financing systems. Amongst the predominantly public systems one can distinguish between those that are predominantly tax-financed and those that are predominantly social insurance-financed. The former, which lie at the top left-hand corner, include Denmark, Ireland, Portugal and the U.K. The latter, which lie at the bottom right-hand corner, include France, the Netherlands and Spain (as of 1980). Only Italy fails to fall into one of the three groups, despite the stated intent of the Italian government to move firmly towards a tax-financed public health care system.

During the 1980 s only two of the 10 countries have significantly changed their location in the health care financing triangle: Spain and Portugal. As Rodriguez et al. (1993) point out, the share of taxes grew rapidly in Spain during the 1980s as an act of policy, and is now larger than the social 
insurance share. Spain has thus moved towards the top left corner in fig. 2. Portugal, by contrast, has seen a rapid rise in the share of health care expenditures financed privately during the $1980 \mathrm{~s}$, with the result that Portugal is now roughly midway between the tax-financed bloc of countries in the top left-hand corner and the predominantly privately-financed bloc of countries towards the bottom left-hand corner.

\section{Measuring equity in the finance of health care}

The requirement that health care be financed according to ability to pay can be interpreted in terms of both vertical equity (in this case the requirement that persons or families of unequal ability to pay make appropriately dissimilar payments for health care) and horizontal equity (the requirement that persons or families of the same ability to pay make the same contribution). The present paper focuses on the former.

In addressing the issue of vertical equity, consideration has to be given to the precise form that the differential treatment of unequals should take. Should those with greater ability to pay be paying more in proportional terms? In other words ought the relationship between ability to pay and payments to be progressive? ${ }^{7}$ Or should they merely be paying more in absolute terms? In other words can the relationship between ability to pay and payments be proportional or even regressive? ${ }^{8}$ If the relationship is to be progressive, how progressive ought it to be? Typically policy statements fail to address questions such as these. In the absence of a clear statement from policy-makers on just how much more the better-off should pay towards health care than the poor, the present study focuses simply on the degree of progressivity. Do the better-off pay a larger proportion of their income on health care than the poor? How progressive or regressive is the relationship between income and payments towards health care? Are some ways of raising revenues more progressive than others? How are these differences reflected in the progressivity characteristics of individual countries" financing systems?

Previous work on progressivity in the finance of health care has been based on tabulations of health care payments by income group [cf. e.g. Hurst (1985); Gottschalk et al. (1989)]. Such tabulations do not, however, enable one to answer the question of how much more (or less) progressive one system (or source of finance) is than another. At best they can indicate whether a system is progressive, regressive or proportional. A more illumi-

\footnotetext{
${ }^{7} \mathrm{~A}$ finance system is progressive if the proportion of income paid out for health care rises as the level of income rises.

${ }^{8} \mathrm{~A}$ finance system is proportional if the proportion of income paid out for health care is the same at all income levels and regressive if the proportion of income paid out falls as income rises.
} 


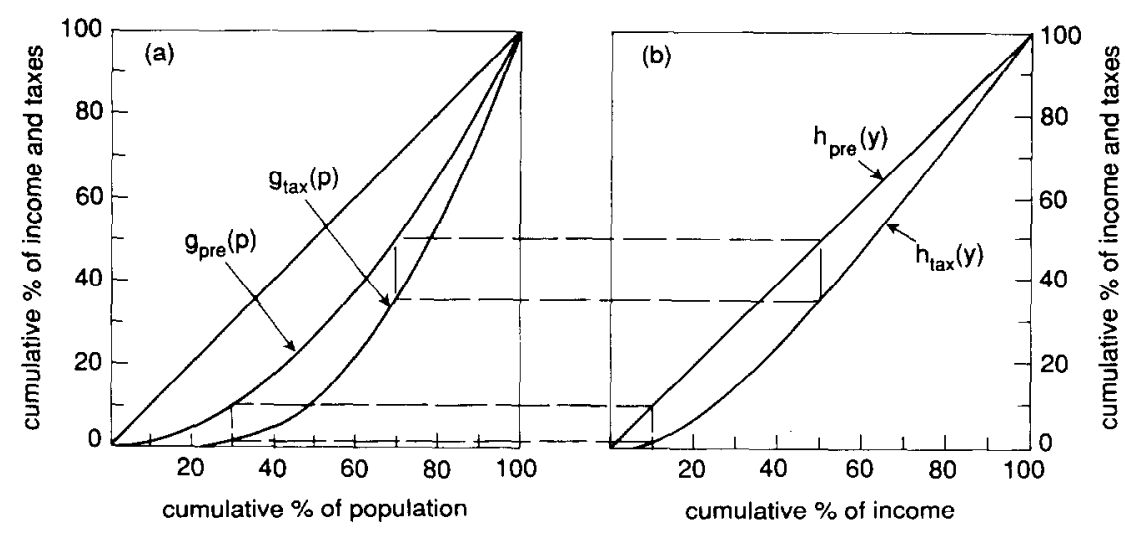

Fig. 3. Kakwani and Suits indices of progressivity.

nating approach to assessing the progressivity of health care financing systems is to employ progressivity indices [cf. Wagstaff et al. (1989)]. A variety of such indices have been proposed in the literature on tax progressivity [Lambert (1989)]. Two such indices - namely those of Kakwani (1977) and Suits (1977) - have been employed in the present study to enable comparisons to be performed both across countries and across financing sources. We outline each index in turn and then compare them.

\subsection{Kakwanis index of progressivity}

Kakwani's index is based on the extent to which a tax system departs from proportionality and can best be illustrated using fig. $3 a$. The curve labelled $g_{\text {pre }}(p)$ is the Lorenz curve for pre-tax income. The second curve - labelled $g_{\text {tax }}(p)$ - is the tax concentration curve, which plots the cumulative proportions of the population (ranked according to pre-tax income as with $g_{\text {pre }}(p)$ ) against the cumulative proportion of tax payments. If taxes are levied strictly in proportion to income, the tax concentration curve and the Lorenz curve for pre-tax income coincide. If the average tax rate rises with income (so that the tax system is progressive), the tax concentration curve lies outside the Lorenz curve for pre-tax income. The opposite is true if taxes are regressive. The degree of progressivity can therefore be assessed by looking at the size of the area between $g_{\text {pre }}(p)$ and $g_{\text {tax }}(p)$. If $G_{\text {pre }}$ is the Gini coefficient for pre-tax income, and $C_{\text {tax }}$ is the concentration index for tax payments, Kakwani's index of progressivity, $\pi_{K}$, is defined as

$$
\pi_{\mathrm{K}}-C_{\mathrm{tax}}-G_{\mathrm{pre}}
$$


which is twice the area between $g_{\operatorname{tax}}(p)$ and $g_{\text {pre }}(p)$. If the system is progressive, as in fig $3 a, \pi_{\mathrm{K}}$ is positive. If, by contrast, the system is regressive, so that $g_{\text {tax }}(p)$ lies above $g_{\mathrm{pre}}(\mathrm{p}), \pi_{\mathrm{K}}$ is negative. The value of $\pi_{\mathrm{K}}$ ranges from - 2.0 (when all pre-tax income is concentrated in the hands of the richest person and the entire tax burden falls on someone else) to 1.0 (when pre-tax income is distributed equally and the entire tax burden falls on one person).

\subsection{Suits' index of progressivity}

Kakwani's index of tax progressivity is based on standard Lorenz and concentration curves. Suits' index, by contrast, is based on what Lambert and Pfähler (1988) call relative concentration curves. The index is illustrated in fig. $3 b$. The curve labelled $h_{\text {pre }}(\mathrm{y})$ is the relative concentration curve for pre-tax income. This plots the cumulative proportion of pre-tax income (starting at the bottom of the distribution) against the cumulative proportion of pre-tax income rather than against the cumulative proportion of the population (as is the case with Kakwani's approach). Thus $h_{\mathrm{pre}}(\mathrm{y})$ coincides with the $45^{\circ}$ line and serves as the benchmark against which to assess progressivity. The curve labelled $h_{\text {tax }}(y)$ plots the cumulative proportion of pre-tax income (starting, as before, at the bottom of the distribution) against the cumulative proportion of tax payments borne by the households in the relevant part of the income distribution. If taxes are levied in proportion to income, $h_{\mathrm{pre}}(\mathrm{y})$ and $h_{\mathrm{tax}}(\mathrm{y})$ coincide, so that, for example, the bottom $10 \%$ of pre-tax income goes to finance $10 \%$ of tax payments. If the tax system is progressive, $h_{\text {tax }}(y)$ lies below the diagonal (the case illustrated). The opposite is true if taxes are regressive. The degree of progressivity can therefore be assessed by looking at the size of the area between $h_{\text {pre }}(y)$ and $h_{\operatorname{tax}}(y)$. If $H_{\operatorname{tax}}$ is the relative concentration index for tax payments, Suits' index of progressivity, $\pi_{s}$, is defined as

$$
\pi_{\mathrm{S}}=H_{\mathrm{tax}}
$$

which is twice the area between $h_{\text {tax }}(y)$ and $h_{\text {pre }}(y)$. If the tax system is progressive, as in fig. $3 \mathrm{~b}, \pi_{\mathrm{s}}$ is positive. If, by contrast, the system is regressive, so that $h_{\mathrm{tax}}(\mathrm{y})$ lies above $h_{\mathrm{pre}}(\mathrm{y}), \pi_{\mathrm{s}}$ is negative. The value of $\pi_{\mathrm{s}}$ ranges from -1.0 (when the entire tax burden falls on the poorest person) to 1.0 (when the entire tax burden falls on the richest person).

\subsection{Properties of the Kakwani and Suits indices}

Formby et al. (1981) have shown that the Suits index gives greater weight to departures from proportionality that occur amongst higher income groups 
than to departures from proportionality occurring amongst lower income groups. This is shown graphically by the lines joining figs. $3 \mathrm{a}$ and $3 \mathrm{~b}$. Thus, for example, the departure from proportionality amongst the bottom $30 \%$ of the population gets a smaller weight in the Suits index than in the Kakwani index: the area between the concentration curve and the benchmark curve is much smaller for the bottom $30 \%$ in the case of the Suits index than in the case of the Kakwani index. ${ }^{9}$

A useful property of both the Kakwani and Suits indices is that the overall index for a tax system consisting of two or more taxes is a weighted average of the indices for the individual taxes, where the weights are the proportions of each tax in total tax revenue [Suits (1977)]. Thus the progressivity characteristics of a health care financing system depend on the proportion of total revenues raised from each source and the degree of progressivity of each of these sources.

Another feature of these progressivity indices is worth mentioning. It is prefectly possible for a source of finance (or a tax) to be progressive (or regressive) at low income levels but regressive (or progressive) at high income levels. Suppose, for example, that pensioners are exempt from social insurance contributions and tend to be located in the lower income groups. Suppose too that contributions are proportional (assume for simplicity to income) but only up to a ceiling. The exemption of pensioners makes the system progressive at low income levels (the bottom income groups will tend to pay a relatively small fraction of their income towards health care) but regressive at high income levels (as a person's income rises above the ceiling, the proportion of their income they pay towards health will fall). The result is that the payment concentration curve will cross from below the relevant benchmark curve (the Lorenz curve in the case of the standard concentration curve and the $45^{\circ}$ line in the case of the relative concentration curve). This is shown in fig. 4 in the casc of the standard concentration curve. Calculating the Kakwani index as the differences between $C_{\text {tax }}$ and $G_{\text {pre }}$ in the case illustrated in fig. 4 implies that the regressivity at high income offsets - at least partially - the progressivity at low incomes. The result could, of course, be a zero value for the progressivity index. Similar remarks apply to the Suits index. In view of the relationship between the two indices shown in figs $3 \mathrm{a}$ and $3 \mathrm{~b}$, it ought to be apparent that where the concentration curves cross their benchmark curves, it is possible for the Kakwani and Suits indices to have opposite signs.

\section{Data, variable definitions and incidence assumptions}

It is clear that in a comparative study of this type, harmonization of

\footnotetext{
${ }^{9}$ We are indebted to the late Peter Ellemann-Jensen for this diagrammatic demonstration of the differences between the two indices.
} 


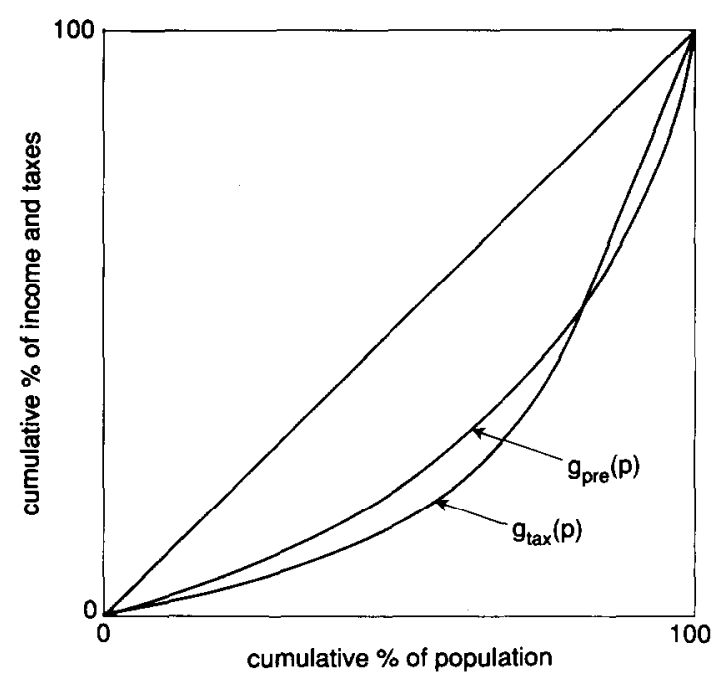

Fig 4. Intersection of $I$ orenz and tax concentration curves

variable definitions is vital. This section describes the data sources, the variable definitions used, and the incidence assumptions employed.

\subsection{Assigning the financing burden}

As is evident from table 1, very few taxes are earmarked for health care. Moreover, in many countries some general social insurance contributions are used to finance health care. Some method is therefore required for deciding which non-earmarked payments actually go towards the financing of health care. In the empirical work reported in this paper, taxes and social insurance contributions that are not earmarked have been allocated pro rata according to the shares of the relevant revenues going to finance health care. This procedure, which is evidently somewhat arbitrary, is equivalent to weighting the progressivity index of each tax or social insurance scheme by its share in total health care expenditures.

Irrespective of whether or not a particular source of health care financing is earmarked, the question arises as to who bears the burden of the payment. Who, for example, bears the burden of - as distinct from "who is liable to pay?' - contributions paid by employers towards social or private health insurance schemes? In principle one would like to bring empirical evidence to bear on this issue, since it is well known that the incidence of a tax depends on the relevant elasticities. For example, the portion of the employer social insurance contribution that is borne by the employee will depend on the 
elasticity of the labour supply curve [Atkinson and Stiglitz (1987)]. In practice, the evidence on incidence is far from clear-cut and one is forced to opt for the less ambitious option of making a set of necessarily arbitrary incidence assumptions. In principle, one could adopt different sets of incidence assumptions for different countries, but this was rejected in the present study on the ground that one could not then be sure whether differences in progressivity were due to differences in financing systems or to differences in, say, labour market conditions. Where possible personal income tax and property taxes were assumed to be borne by the tax-payers concerned, corporate income taxes by shareholders, sales and excise taxes by consumers, and employee and employer social insurance contributions by employees.

\subsection{Data and variable definitions}

Typically - though not always - the rules governing health care payments (especially taxes and health insurance premiums) apply to families or households rather than individuals. Thus measuring the progressivity of health care financing systems requires household-level ${ }^{10}$ data on pre-tax income and health care payments, with the latter broken down into (i) taxation, (ii) social insurance contributions, (iii) private insurance premiums, and (iv) out-of-pocket payments. The surveys used to analyse progressivity in the finance of health care in the 10 countries in the present study are listed in table 2 .

Gross (i.e. pre-tax) income was employed as the benchmark against which to assess progressivity: gross income includes wage income as well as nonwage income (e.g. cash transfers, cash property income, etc.). Not all surveys contain information on pre-tax income, in which case countries have had to estimate it from data on post-tax income. In all but the American and British results the gross income figure was converted to a per-equivalent-adult basis in order to take into account the variation in household structure that exists across families, with countries using whichever equivalence scale they felt to be appropriate. ${ }^{11}$

None of the surveys listed in table 2 is sufficiently comprehensive to allow the entire financing burden to be allocated across income groups using only

\footnotetext{
${ }^{10}$ Rules relating to the finance of health care, especially those concerning private health insurance, often apply to the family rather than the household. The latter, however, is typically the income-sharing unit and hence is arguably the more appropriate for assessing how health care payments relate to ability to pay.

${ }^{1}$ The argument for employing different equivalence scales is that the circumstances of countries differ. The argument against this strategy is that use of different sales would be to invite the response that any inter-country differences emerging in the consequent results simply reflected these equivalence scale differences.' [O'Higgins, Schmaus and Stephenson (1990; 25)]. Health care payments were not equivalized in the calculation of the concentration indices.
} 
Table 2

Surveys used in progressivity analysis.

\begin{tabular}{|c|c|c|c|c|c|}
\hline Country & Abbr. & Year & Survey(s) & $\begin{array}{l}\text { Institution } \\
\text { conducting survey }\end{array}$ & $\begin{array}{l}\text { No. of } \\
\text { households }\end{array}$ \\
\hline Denmark & DK & 1981 & $\begin{array}{l}\text { Household Expenditure } \\
\text { Survey }\end{array}$ & Danmarks Statistik & 2,783 \\
\hline France & $\mathrm{F}$ & 1984 & Family Expenditure Survey & INSEE & 11,977 \\
\hline Ireland & IRL & 1987 & Household Budget Survey & $\mathrm{CSO}$ & 7,705 \\
\hline Italy & I & 1987 & Family Consumption Survey & ISTAT & 3,164 \\
\hline Netherlands & NL & 1987 & $\begin{array}{l}\text { Household Expenditure } \\
\text { Survey }\end{array}$ & CBS & 2,750 \\
\hline Portugal & $\mathrm{P}$ & 1981 & $\begin{array}{l}\text { Family Income and } \\
\text { Expenditure Survey }\end{array}$ & INE & 8,054 \\
\hline Spain & $\mathrm{E}$ & 1980 & Family Budget Survey & INE & 23,972 \\
\hline Switzerland & $\mathrm{CH}$ & 1982 & $\begin{array}{l}\text { SOMIPOPS and SEVS } \\
\text { surveys }\end{array}$ & $\begin{array}{l}\text { National Science } \\
\text { Foundation }\end{array}$ & 3,835 \\
\hline U.K. & U.K. & 1985 & Family Expenditure Survey & $\mathrm{CSO}$ & 7,000 \\
\hline U.S. & U.S. & 1980 & NMCUES & $\begin{array}{l}\text { National Center for } \\
\text { Health Statistics }\end{array}$ & 6,000 \\
\hline
\end{tabular}

information recorded in the survey. Some surveys, for example, do not contain information on property taxes. Authors have had therefore to explore alternative data sources for at least some sources of finance, or else make informed guesses as to the distribution of the omitted categories.

Fig. 5 shows the proportion of revenues allocated from each of five data sources. The first source is the raw data of the principal survey used in the analysis - the survey listed in table 2. This source is the most flexible. The second category is published tabulated data that have been derived from the principal survey by other researchers. The U.K. results, for example, have been derived using tables published by the Central Statistical Office based on data from the British Family Expenditure Survey. The disadvantage of pretabulated data is obvious: researchers have no option but to live with the definitions adopted by the persons who have done the tabulations. Households may, for example, have been ranked by income or equivalent expenditure, instead of equivalent income. The third category is data from other surveys. Sometimes the survey is in the same series but another year: the Irish and U.K. results, for example, are based in part on data from previous years of the primary survey. Alternatively the survey can be another survey entirely: the Dutch results, for example, are based in part on tabulations of indirect taxes from a survey other than the principal survey. The fourth category comprises estimated distributions. This is where researchers did not have access to data on the variable in question but have been able to estimate its distribution across income groups by using information from other studies. The distribution of semi-private insurance premiums in the Swiss rcsults, for example, have been estimated by drawing 


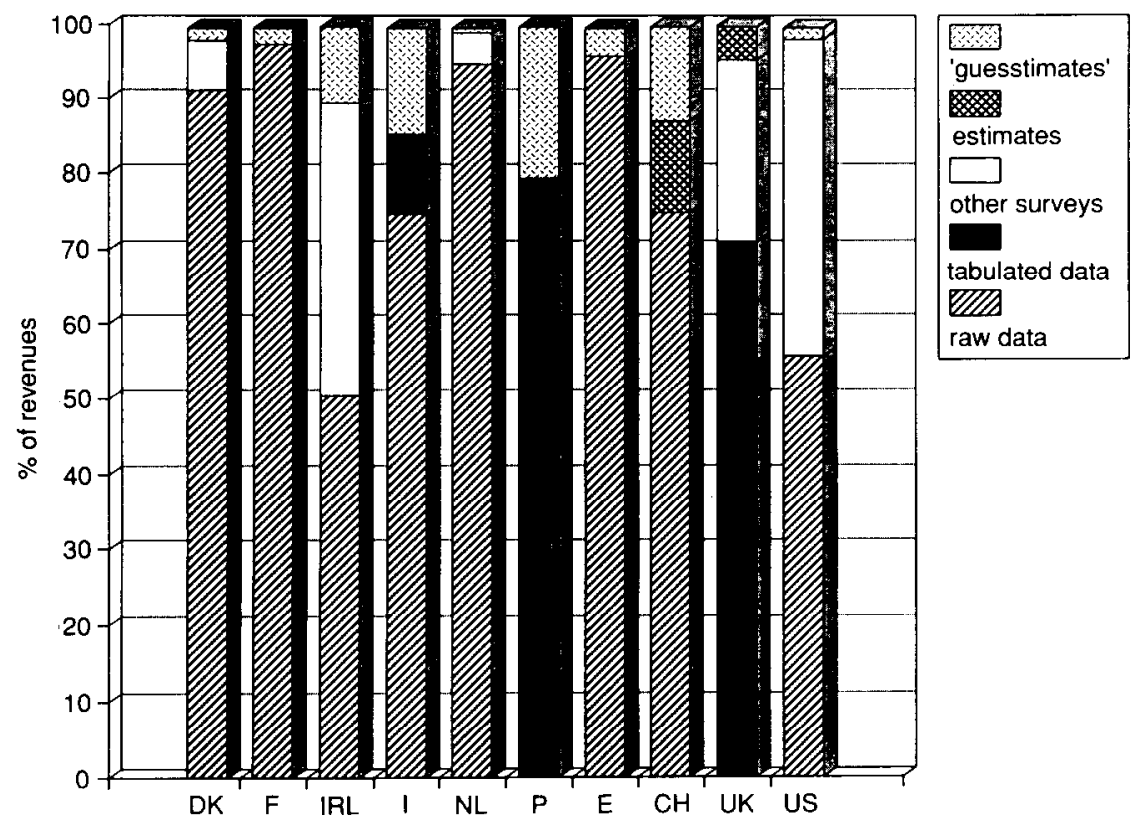

Fig. 5. Breakdown of data sources used.

on econometric estimates of the income-elasticity of demand for this type of insurance. The fifth category comprises 'guesstimates'. Some of these are more informed than others. Omitted indirect taxes, for example, have often been assumed to be distributed as the indirect taxes that have been allocated from survcy data. Occasionally no explicit assumption has been made. If only part of a category has been allocated on the basis of survey data, but the progressivity index has been weighted by the full share of the financing source, the implicit assumption is that the omitted part is distributed as the included part. If, by contrast, the source is omitted completely, the implicit assumption is that the source is distributed as the overall burden of included sources.

As is apparent from fig. 5, in most cases over $90 \%$ of revenues were allocated using raw survey data, tabulated data or data from other surveys. Exceptions to this are Ireland and Italy, where nearly $90 \%$ has been allocated from survey data, and Portugal and Switzerland, where the distribution of more than $20 \%$ of revenues had to be estimated to 'guesstimated'. For the most part the gaps are in the distributions of taxes, though in Switzerland and the U.K. the distributions of some non-tax revenues had to be estimated or 'guesstimated'. 


\section{Empirical results}

Table 3 reports the Kakwani and Suits indices for each of the 10 countries' health care financing systems, as well as for their constituent parts. ${ }^{12}$

\subsection{Taxes}

As noted above, most direct taxes other than personal income tax have not been allocated, so most direct tax distributions reflect only this tax. Unsurprisingly, dircet taxcs arc progressive in all countries, though the degree of progressivity varies. According to table 3, the countries with the most progressive direct tax systems are Portugal and Ireland, and the country with the least progressive system is Italy. The latter provides a nice example of the need to look beyond the rate structure when assessing progressivity: in 1987 the Italian personal income tax system contained no less than nine bands, but because so few people paid tax at the higher rates, the system was relatively unprogressive.

In most countries indirect taxes are regressive, this being particularly so in Ireland and the U.S. The fact that indirect taxes are progressive in Italy, Portugal and Spain, is due to higher VAT rates being levied on luxury goods.

The overall progressivity of the tax system can be calculated as a weighted average of the Kakwani (or Suits) indices for direct and indirect taxes, where the weights correspond to the shares of each tax in total tax revenues. In all eight countries general taxes are at least proportional (Denmark) and are generally progressive, though - unsurprisingly - less so than direct taxes. ${ }^{13}$

\subsection{Social insurance}

In the three countries operating social insurance-based health care financing systems - France, the Netherlands and Spain - social insurance is regressive. ${ }^{4}$ This stems from the fact that contributions tend to be proportional to earnings only up to a ceiling. These systems would, however, be

\footnotetext{
${ }^{12}$ The results reported in this section are taken from van Doorslaer, Wagstaff and Kutten (1993), except in the case of Italy, where the revised results reported in Paci and Wagstaff (1993) have been used.

${ }^{13}$ See van Doorslaer, Wagstaff and Rutten (1993) for further results.

${ }^{14}$ The progressivity index in the case of the Netherlands reflects only contributions to the AWBZ scheme for coverage against catastrophic expenses. Premiums paid by the bottom and middle income groups to sickness funds for non-catastrophic cover have been labelled as 'private', since these were included under the same heading in the Dutch Household Expenditure Survey as the private premiums paid by the top income group for the same cover. Because people pay either one premium or the other depending on their earnings, including the sickness fund premiums with the AWBZ premiums (which are paid by everyone) rather than private premiums would make social insurance more regressive and private insurance more progressive.
} 


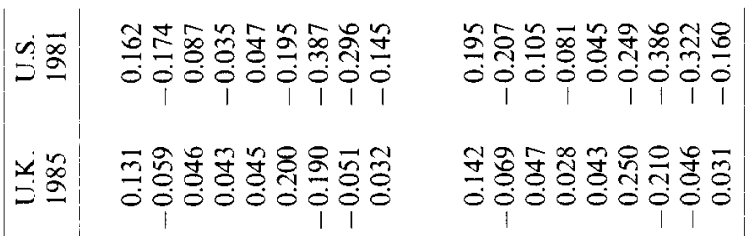

$\stackrel{\frac{c}{2}}{\frac{2}{5}}$

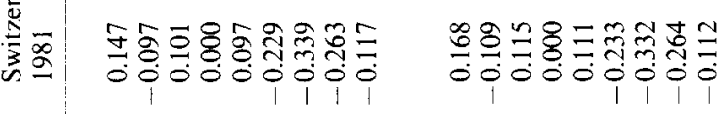

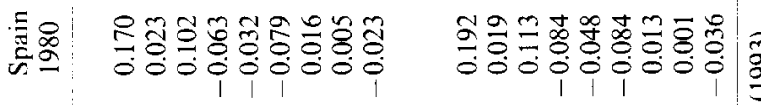

高

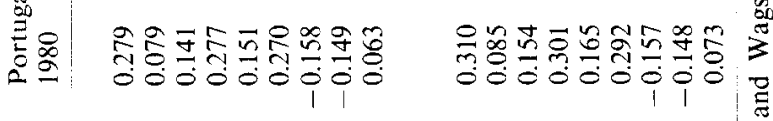

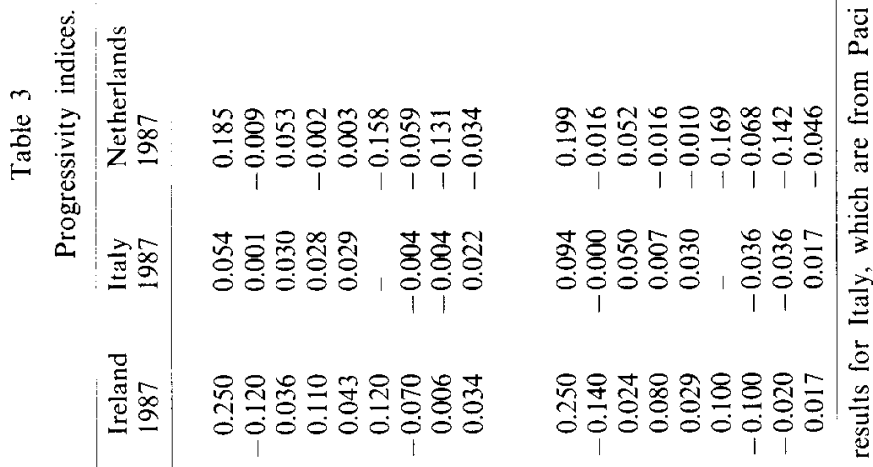

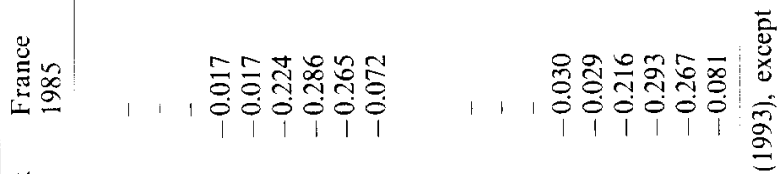

密

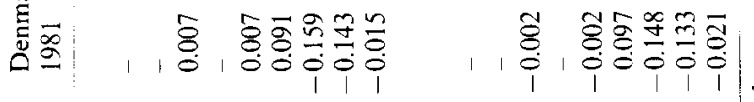

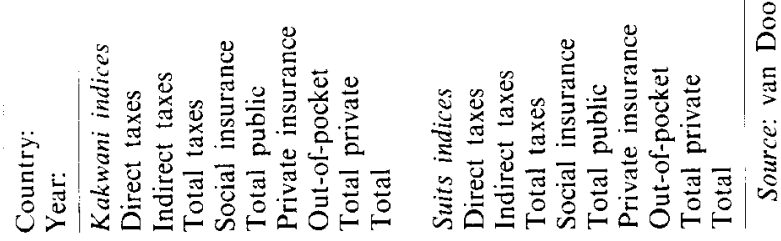




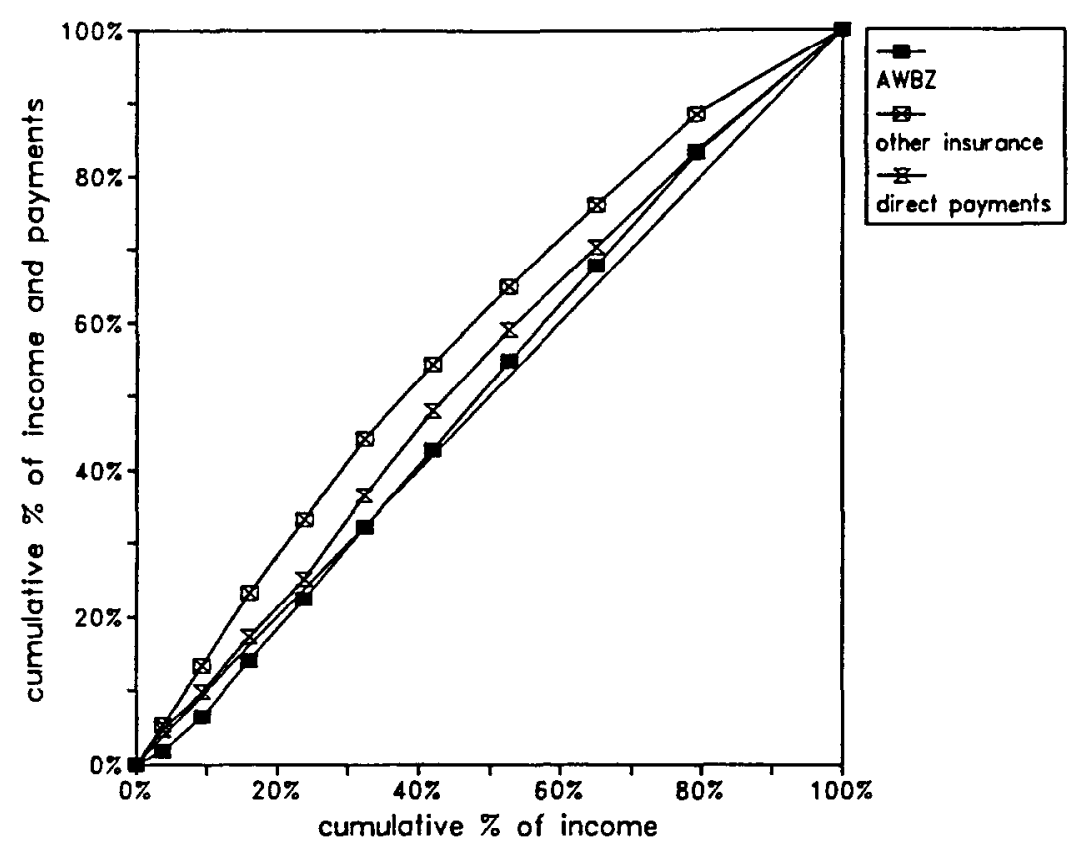

Fig. 6. Relative concentration curves for the Netherlands.

even more regressive if groups such as pensioners were not exempt from contributions, as in, for example, the Netherlands and Spain, or did not face reduced contribution rates, as they do, for example, in France. In such countries, social insurance is actually progressive at low income levels. The Dutch case is illustrated in fig. 6.

In Italy, where health-specific social insurance contributions still play a major role in the finance of public health care, social insurance is actually mildly progressive. This is despite the fact that the marginal contribution rate actually declines with earnings. One reason may be that whilst contributions may be regressive on earnings, they may be proportional - or even progressive - on income. Another is the fact that different groups are treated differently within the Italian social insurance system. Pensioners, for example, are exempt from social insurance contributions, as they are in some other countries. Another explanation is that professional groups face different contribution schedules, with persons who face the lower average contribution rates tending to have relatively small declared incomes.

The progressivity of the Portuguese social insurance scheme stems from the fact that although contributions to the scheme are earnings-related and compulsory, the scheme is not universal, covering and requiring contribu- 
tions from only certain employees, the majority of these working in the public sector. Its progressivity is due to the fact that these workers tend to be in the higher income groups (the top decile alone contributed $42 \%$ of the scheme's revenues).

In both Ireland and the U.K., where there are no earmarked social insurance contributions or where earmarking plays only a small role, social insurance is progressive, whereas in the U.S., where a percentage of social insurance is earmarked for public health care, social insurance is regressive.

\subsection{Private insurance}

In interpreting the results on private health insurance it is important to bear in mind the cover that private insurance buys in each country. Broadlyspeaking, three groupings emerge from table 1, the exception being Ireland, which, as indicated above, spans all three groups.

The first comprises countries where private insurance buys cover against public sector co-payments and includes Denmark and France. The fact that private insurance against public sector co-payments is progressive in Denmark but regressive in France reflects the fact that private insurance against public sector co-payments is more widespread in France than in Denmark. This in turn reflects the higher co-payments in France.

The second group comprises countries where private insurance is mostly taken out as supplementary cover (mostly 'double' cover) to that provided by the State and includes Italy, Portugal and the U.K. Private insurance of this type is progressive, which suggests that such insurance is a 'luxury' good.

The third group comprises countries where, for the individual concerned, private insurance is (or is nearly) the sole source of cover. This group includes the Netherlands, Spain, Switzerland and the U.S. Switzerland is unusual in this group in that private insurance is bought by almost everyone. In the other three countries, private insurance is generally taken out only by persons with restricted or non-existent public cover. ${ }^{15}$ In the U.S. persons purchasing private insurance as their sole source of cover make up the bulk of the population, whilst in Ireland, the Netherlands and Spain they comprise $29 \%, 39 \%$ and $15 \%$ of the population, respectively. ${ }^{16}$ As is apparent from table 3 , where it is relied upon by the majority of the population for cover, as in Switzerland and the U.S., private insurance is highly regressive. 'The highly negative Dutch index value stems from the fact that the figures include not only the genuinely private cover bought by the $39 \%$ of the population with private insurance, but also the non-catastophic cover bought by the remaining $61 \%$ of the population from sickness funds. Had only the

\footnotetext{
${ }^{15}$ In the U.S. a small proportion of expenditures on private insurance is accounted for by persons with public cover purchasing supplementary insurance.

${ }^{16}$ Figures refer to 1987.
} 
former been included, private insurance would have emerged as being progressive, as it is in Ireland where private insurance is taken out mainly by the better off. ${ }^{17}$ The fact that private insurance is regressive in Spain in the year in question reflects the fact that many of those taking out private insurance were the self-employed who neither had public cover nor were particularly well-off.

\subsection{Out-of-pocket payments}

Out-of-pocket payments tend to be a highly regressive means of financing health care. In all countries in the study except Spain, such payments were regressive. There is, however, some variation across countries. That out-ofpocket payments were only midly regressive in Ireland and the Netherlands in 1987 stems from the fact that the private cover taken out by persons in the higher income groups without comprehensive public cover was either not comprehensive or required co-payments. In Ireland persons in the top $62 \%$ of the income distribution were required to pay for GP visits and prescription drugs in full, while in the Netherlands much of the expenditures associated with out-of-pocket payments were incurred by the privately insured in the upper half of the income distribution having insurance policies with substantial deductibles or excluding primary care. That out-of-pocket payments are so regressive in Switzerland and the U.S. stems from the fact that - with the exception of Medicaid enrollees and some privately insured in the U.S. - co-payments are paid by all irrespective of their income.

\subsection{Overall cross-country differences in progressivity of financing systems}

It is striking that in only three countries - the U.K., Ireland and Portugal - is health care finance progressive. Also striking is that the progressivity indices for total health care payments fall into the same three clusters that emerged in the health care financing triangle in fig. 2 . The two countries with predominantly private financing systems - Switzerland and the U.S. - have the most regressive structures overall. This is scarcely surprising in view of how regressive private insurance and out-of-pocket payments are when used to finance such a large proportion of health care expenditures for such a large proportion of the population. The group of countries with the next most regressive financing systems are the countries operating the so-called social insurance model, notably France, Spain and the Netherlands. That these countries' systems are less regressive than those of Switzerland and the U.S. is partly because social insurance is less regressive than private

\footnotetext{
${ }^{17}$ The top three deciles of equivalent gross income in Ireland accounted for $66 \%$ of expenditures on private insurance premiums.
} 
insurance, partly because there is less reliance on out-of-pocket payments in the second group of countries, and partly because persons in the lower income groups in the latter countries tend to be less likely to be called on to make out-of-pocket payments. The final group of countries, which include Denmark, Ireland, Portugal and the U.K., rely mainly on tax-finance and have the least regressive financing systems. Indeed, in the U.K., Ireland and Portugal health care finance is, as has been noted, marginally progressive.

\section{Summary and Conclusions}

Health care is typically financed from a mixture of four sources: taxes, social insurance contributions, private insurance premiums, and out-ofpocket payments. The precise mix varies from one country to the next. Amongst the countries that finance the bulk of their expenditures publicly, a distinction is made between tax-financed systems (Denmark, Ireland, Portugal and the U.K.) and social insurance systems (France, the Netherlands and Spain). Few countries finance the bulk of their expenditures privately: only in Switzerland and the U.S. do private insurance premiums and out-of-pocket payments combined exceed $50 \%$.

On standard incidence assumptions, taxes are typically a progressive means of raising revenue. The overall degree of progressivity of taxation depends on the progressivity of each tax and the precise mix used. Typically direct taxes are progressive and indirect taxes regressive. Thus in principle, if direct taxes are insufficiently progressive, and/or there is a sufficiently strong emphasis on indirect taxes in the financing of health care, the tax burden overall could be regressive. In none of the countries in the present study, however, does this appear to be the case.

Social insurance, by contrast, tends to be a regressive method of raising revenue. This is typically because contributions are subject to a ceiling, though in some countries the marginal contribution rates themselves decline as earnings rise. There are, however, progressive elements to social insurance: for example, certain groups, such as pensioners, are typically exempt from contributions. Overall, however, social insurance tends to be regressive.

The same is true of private insurance in countries such as Swizerland and the U.S., where the majority of the population has no public insurance cover. Indeed private insurance is a more regressive method of raising revenue than is social insurance, the reason being that whereas the latter is assessed on the basis of earnings, at least up to a point, the former is not. To the extent that private insurance premiums are adjusted for risk, premiums may actually be negatively related to income, since the worse-off tend to be in relatively poor health. Only in countries like the U.K., where private insurance buys supplementary cover, and in countries like Ireland and the Netherlands, where private insurance is taken out mainly by the better-off, who have 
limited public cover, is private insurance progressive. This simply reflects the fact that private insurance in these countries is purchased only by the betteroff. To the extent that further expansion of private insurance in these countries can only come about as a result of persons in the middle and lower income groups also taking out private insurance, such expansion would make private insurance less progressive. Indeed, at some point such expansion would render private insurance regressive, as it is already in Switzerland and the U.S.

Out-of-pocket payments are also generally a regressive form of health care finance. Such payments tend to be substantially more regressive than social insurance, and in countries where private insurance is widespread, they tend to be even more regressive than private insurance premiums. ${ }^{18}$ In taxfinanced systems, out-of-pocket payments are typically the only regressive elements in the financing system, apart from indirect taxes. The regressiveness of out-of-pocket payments stems, of course, in part from the higher rates of sickness and medical consumption of the worse-off.

Given the above, it should come as no surprise that while tax-financed health care systems (such as those operating in Denmark, Ircland, Portugal and the U.K.) tend to be mildly progressive or proportional, social insurance systems (such as those operating in France, the Netherlands and Spain) and predominantly private systems (such as the American and Swiss systems) tend to be regressive, with the latter systems being particularly regressive.

These results have clear implications for some of the broad-brush health care reforms proposed in the OECD countries. A switch from social insurance to tax-financing, as has occurred recently in Spain and was planned for Italy following the setting up of the Italian national health service in 1978, is likely to make health care finance more progressive and may even turn a regressive system into a progressive one. A greater emphasis on public financing in a predominantly private system, as is advocated by many American and Swiss commentators, would reduce the overall regressiveness of the health care financing systems of these countries and might even result in progressive financing systems, depending on the precise model adopted. A greater emphasis on out-of-pocket payments, as has happened recently in France and several other OECD countries, is likely to make health care financing less progressive or more regressive.

\section{Appendix: Authors and Affiliations}

Samuel Calonge, University of Barcelona, 08034 Barcelona, Spain. Terkel Christiansen, Odense University, 5320 Odense M, Denmark. Michael Gerfin, University of Bern, 3012 Bern, Switzerland.

\footnotetext{
${ }^{18}$ Portugal is, as has been seen, an exception to this.
} 
Peter Gottschalk, Boston College, Chestnut Hill, MA 02167, U.S.A.

Richard Janssen, Limburg University, 6200 MD Maastricht, Netherlands.

Claire Lachaud, University of Lyon 1, 69622 Villeurbanne cedex, France.

Robert E. Leu, University of Bern, 3012 Bern, Switzerland.

Brian Nolan, Economic and Social Research Institute, Dublin 4, Ireland.

Owen O'Donnell, University of York, York YO1 5DD, U.K.

Pierella Paci, City University, London EC1V 0IIB, U.K.

João Pereira, National School of Public Health, 1699 Lisbon Codex,

Portugal.

Carlos Gouveia Pinto, Lisbon Technical University, 1200 Lisbon, Portugal.

Carol Propper, University of Bristol, Bristol BS8 1TH, U.K.

Joana Reñé, SOIKOS, 08028 Barcelona, Spain.

Lise Rochaix, University of Lyon 1, 69622 Villeurbanne cedex, France.

Marisol Rodriguez, University of Barcelona, 08034 Barcelona, Spain.

Frans Rutten, Erasmus University, 3000 DR Rotterdam, Netherlands.

Richard Upward, University of Bristol, Bristol BS8 1TH, U.K.

Eddy van Doorslaer, Erasmus University, 3000 DR Rotterdam, Netherlands.

Adam Wagstaff, University of Sussex, Brighton BN1 9QN, UK.

Barbara Wolfe, University of Wisconsin, Madison, WI 53706, U.S.A.

\section{References}

Atkinson, A.B. and J.E. Stiglitz, 1987, Lectures of public economics (McGraw-Hill, London).

Culyer, A.J., A. Maynard and A. Williams, 1981, Alternative systems of health care provision: An essay on motes and beams, in: M. Olson, ed., A new approach to the economics of health care (American Enterprise Institute, Washington).

Formby, J.P., T.G. Seaks and W.J. Smith, 1981, A comparison of two new measures of tax progressively, Economic Journal 91, 1015-1019

Gerdtham, U.G., J. Søgaard, F. Andersson and B. Jönsson, 1992, An econometric analysis of health care expenditure: A cross-section study of the OECD countries, Journal of Health Economics 11, 63-84.

Gillon, R., 1986, Philosophical medical ethics (Wiley, Chichester).

Gottschalk, P., B. Wolfe and R. Haveman, 1989, Health care financing in the U.S., U.K. and Netherlands: Distributional consequences, in: A. Chiancone and K. Messere, eds., Changes in revenue structures (Wayne State University Press, Detroit).

Hurst, J.W., 1985, Financing health services in the United States, Canada and Britain (King Edward's Hospital Fund, London).

Hurst, J.W., 1992, The reform of health care: A comparative analysis of seven OECD countries (OECD, Paris)

Kakwani, N.C., 1977, Measurement of tax progressivity: An international comparison, Economic Journal $87,71-80$.

Lambert, P.J., 1989, The distribution and redistribution of income: A mathematical analysis (Blackwell, Oxford).

Lambert, P.J. and W. Pfähler, 1988, On aggregate measures of the net redistributive impact of taxation and government expenditure, Public. Finance Quarterly 16, 178-202

Le Grand, J., 1987, Equity, health and health care, Social Justice Research 1, 257-274.

McLachlan, G. and A. Maynard, 1982, The public/private mix in health care: The emerging lessons, in: G. McLachlan and A. Maynard, eds., The public/private mix in health care: The relevance and effects of change (Nuffield Provincial Ilospitals Trust, London). 
Maxwell, R.J., 1981, Health and wealth: An international study of health care spending (Lexington, Lexington, MA).

Mooney, G., 1986, Economics, medicine and health care (Wheatsheaf, Brighton).

OECD, 1989, Health care expenditure and other data: An international compendium, Health Care Financing Review Annual Supplement, 111-194.

O'Higgins, M., G. Schmaus and G. Stephenson, 1990, Income distribution and redistribution: A microdata analysis for seven countries, in: T. Smeeding et al., eds., Poverty, inequality and income distribution in perspective: the Luxembourg income study (Harvester, London).

Paci, P. and A. Wagstaff, 1993, Equity and efficiency in Italian health care, Health Economics, forthcoming.

Peet, J., 1991, Surgery needed: A survey of health care, The Economist, July 6.

Rodriguez, M., S. Calonge and J. Reñé, 1993, Equity in the finance and delivery of health care in Spain, in: E. van Doorslaer, A. Wagstaff and F. Rutten, eds., Equity in the finance and delivery of health care: An international perspective (Oxford University Press, Oxford).

Schieber, G.J. and J.P. Poullier, 1991, International health care spending: Issues and trends, Health Affairs 10, 106-116.

Suits, D., 1977, Measurement of tax progressivity, American Economic Review 67, 747-752.

Van Doorslaer, E., A. Wagstaff and F. Rutten, eds., 1993, Equity in the finance and delivery of health care: An international perspective (Oxford University Press, Oxford).

Van Doorslaer, E., A. Wagstaff and others, 1992, Equity in the delivery of health care: Some international comparisons, Journal of Health Economics 11, 389-411.

Wagstaff, A., E. van Doorslaer and P. Paci, 1989, Equity in the finance and delivery of health care: Some tentative cross-country comparisons, Oxford Review of Economic Policy 5, $89-112$ 